3. When $\mathrm{Na}^{+}$is excreted under similar conditions into $0 \cdot 1 \mathrm{M}-\mathrm{KCl}$ with $\mathrm{NaCl}$ ranging from zero to $1.0 \mathrm{M}$, little reduction in the rate of $\mathrm{Na}^{+}$excretion occurs up to an external $\mathrm{Na}^{+}$value of $0.2 \mathrm{M}$. At an external value of $0.43 \mathrm{M}$ the $\mathrm{Na}$ excretion is approximately $50 \%$ that at zero $\mathrm{Na}^{+}$concentration.

4. The existence of two separate carriers for $\mathrm{Na}$ (outwards) and for $\mathrm{K}$ (inwards) is shown by the relative specificity of the transport in each case and the different action of inhibitors. Where $\mathrm{Na}$ ions $(0.1 \mathrm{M})$ without any $\mathrm{K}$ ions are present in the suspending fluid $\mathrm{Na}$ ions can be carried inwards on what may be regarded as normally the $K$ carrier.

5. The $\mathrm{Na}$ carrier excreting $\mathrm{Na}$ is inhibited by cyanide $(0.002 \mathrm{M})$ and anoxia; it is not inhibited by azide $(0.002 \mathrm{M})$ or 2:4-dinitrophenol $(0.002 \mathrm{M})$.

6. The $\mathrm{K}$ carrier involved in the uptake of $\mathrm{K}^{+}$(or of $\mathrm{Na}^{+}$if no $\mathrm{K}^{+}$is present outside, and $\mathrm{Na}^{+}$is present in quantity) is inibited by anoxia, and by cyanide, azide and 2:4-dinitrophenol at concentration of $0.002 \mathrm{M}$.

7. The results are shown to support strongly the theory of a 'redox pump' for the biological performance of osmotic work.

8. Various metallic ions can greatly inhibit the active excretion of $\mathrm{Na}$ ions into $0 \cdot 1 \mathrm{M}-\mathrm{KCl}$. Inhibition depends on the magnitude of the atomic number and on the presence of 18 electrons in the second outermost orbit, and not more than two in the outermost.

Our thanks are due to the Rockefeller Foundation and to the Medical Research Council of Ireland for grants in aid.

\section{REFERENCES}

Boyle, P. J. \& Conway, E. J. (1941). J. Physiol. 100, 1.

Conway, E. J. (1950a). Microdiffusion Analysis and Volumetric Error, 3rd ed. London: Crosby Lockwood.

Conway, E. J. (1950b). Irish J. Med. Sci., ser. 6, no. 293.

Conway, E. J. (1951). Science, 113, 270.

Conway, E. J. (1952a). Biochemistry of Gastric Acid Secretion. Illinois: Thomas.

Conway, E. J. (1952b). Ciba Foundation Colloquia on Endocrinology, 4, 417. London: Churchill.

Conway, E. J. (1953). International Review of Cytology, ed. by Browne, G. and Danielli, J. F., New York: Academic Press.

Conway, E. J. \& Brady, T. G. (1947). Nature, Lond., 159, 137.

Conway, E. J., Brady, T. G. \& Carton, E. (1950). Biochem. $J .47,3$.

Conway, E. J. \& Downey, M. (1950). Biochem. J. 47, (3) 347.

Conway, E. J. \& Hingerty, D. (1948). Biochem. J. 42, 372.

Conway, E. J. \& Moore, P. T. (1952). 2nd Int. Congress Biochem. Abstr. p. 141.

Conway, E. J. \& Moore, P. T. (1954). Biochem. J. 57, 523.

Desmedt, J. E. (1953). J. Physiol. $121,191$.

Spiegelman, S., Kamen, M. D. \& Sussman, M. (1948). Arch. Biochem. 18, 409.

Steinbach, H. B. (1951). Amer. J. Physiol. 167, 284.

\title{
Studies of Sebum
}

\section{THE COMPOSITION OF SOME SEBUM-LIKE MATERIALS OF HUMAN ORIGIN}

\author{
BY V. R. WHEATLEY \\ Departments of Biochemistry and Dermatology, Medical College of St Bartholomew's Hospital, E.C. 1
}

(Received 20 April 1954)

Apart from true sebum or surface-skin lipid there exist a number of materials which are alleged to originate from true or modified sebaceous glands. Some of these materials such as cerumen or ear wax, smegma and vernix caseosa are normal in origin while others, for instance dermoid cyst lipid, are pathological. The latter material is of interest. Dermoid cysts frequently grow to relatively enormous size in the ovaries; the cysts are hollow and are lined with what appears to be epidermal tissue. The cyst is usually filled with a mixture of water, fatty material and hair. The fatty material has long been thought to be sebum (Sotnitchewsky, 1880), and while it has been investigated by numerous workers, no direct comparison has been made between its composition and that of sebum.

In order to obtain information about the origin of these sebum-like materials, ovarian dermoid cyst lipid, ear wax, vernix caseosa and epidermal cyst lipid have been analysed and the results are compared with those obtained with sebum (MacKenna, Wheatley \& Wormall, 1950, 1952). Preliminary reports of part of this work have already been published (Wheatley, 1951, 1953a).

\section{EXPERIMENTAL}

\section{Materials}

Fatty material was obtained from two ovarian dermoid cysts and was found to contain little water. It dissolved readily in $\mathrm{CHCl}_{3}$, and the lipid which remained after filtering and evaporating this $\mathrm{CHCl}_{8}$ solution to dryness was analysed. Ear wax was obtained from European patients of this hospital and contained much dirt and extraneous material. The lipid was extracted from both single samples and bulked specimens by refluxing the material with $\mathrm{CHCl}_{2}$ 
and filtering off the extraneous matter. The vernix caseosa was obtained by gently scraping the skin of newly born babies with a glass slide. The epidermal cyst was excised from a patient attending this hospital. Both these materials contained appreciable amounts of water, they were first dehydrated by refluxing with acetone and then extracted with $\mathrm{CHCl}_{3}$. The combined acetone and $\mathrm{CHCl}_{3}$ extracts were then evaporated to dryness and the last traces of water removed by adding small amounts of acetone and carefully distilling this off. The residue was then dissolved in warm $\mathrm{CHCl}_{3}$, the solution filtered and evaporated to dryness.

\section{Analytical methods}

All melting points recorded here are uncorrected; microanalyses were performed by Weiler and Strauss, Oxford.

Chemical constants. Iodine numbers and acid numbers were determined on suitable samples by the methods described in earlier work (MacKenna et al. 1950; HodgsonJones \& Wheatley, 1952). Cholesterol was determined by the method of Kelsey (1939), phosphorus by the method of Fiske \& Subbarow (1925) after digestion with $\mathrm{H}_{2} \mathrm{SO}_{4}$ and $\mathrm{HNO}_{3}$, and nitrogen by a micro-Kjeldahl method.

Fractionation. The lipids were fractionated into free fatty acids, combined fatty acids and unsaponifiable matter by the method used for sebum (MacKenna et al. 1950). A heavy interface precipitate was formed when alkali was added to the ethereal solution of both ear wax and vernix caseosa; this rendered separation difficult.

Chromatography of the unsaponifiable matter. The method described for sebum unsaponifiable matter (MacKenna et al. 1952) was used. In most cases a sample of $1 \mathrm{~g}$. was fractionated on a $20 \mathrm{~g}$. column of alumina (Brockmann, grades IIIII); with larger quantities of unsaponifiable matter correspondingly bigger columns were used. An attempt was made to replace the $\mathrm{CHCl}_{3}$-petroleum mixtures, used as eluents, by simple substances (benzene, ether, etc.), as recommended by Nicolaides \& Rothman (1953), but it was found that in order to obtain good separation with these solvents very careful selection of the alumina was necessary. For example, with grade II alumina benzene failed to elute the wax-alcohol fraction, while with grade III alumina benzene eluted both the wax alcohols and cholesterol. It was therefore decided to retain the use of mixed solvents and to follow the development of the chromatogram by collection of $100-300 \mathrm{ml}$. portions of eluate.
With both ear wax and vernix caseosa there was an appreciable amount of material which was insoluble in light petroleum and caused blocking of the column during the early stages of the chromatography. It was found that this blocking could be prevented if the column was covered with a thin layer of sand (2-3 mm. thick) before loading.

Paper chromatography. Alumina-impregnated paper was prepared as described by Bush (1952) and stored over saturated $\mathrm{CaCl}_{2}$ soln. (relative humidity about $30 \%$ ). The chromatograms were run by the ascending method using either benzene-light petroleum (b.p. 80-100'), benzene$\mathrm{CHCl}_{3}$ mixtures (equal parts by volume) or pure $\mathrm{CHCl}_{3}$. The chromatogram was then sprayed with $\mathrm{SbCl}_{3}$ in $\mathrm{CHCl}_{3}$ and heated in an oven at $90^{\circ}$ for about $3 \mathrm{~min}$. A blue spot showed the presence of sterol-like substances. The activity of the paper varied slightly with each batch and the $R_{F}$ values given below refer to individual experiments only. The presence of a particular substance was established by running three parallel chromatograms of the unknown substance, the authentic compound and a mixture of both. Fuller details of the paper chromatography procedures will be given in a subsequent paper.

Identification of squalene. Squalene was isolated as the hexahydrochloride in the following manner. The hydrocarbon fraction obtained by chromatography of the unsaponifiable matter was dissolved in either acetone or ether. The solution was cooled to $-5^{\circ}$ and saturated with dry $\mathrm{HCl}$ gas. After the mixture had been allowed to stand for several hours, the precipitate was collected, washed thoroughly with light petroleum to remove adhering hydrocarbons and twice recrystallized from acetone. The crystals thus obtained were submitted for analysis; only when a correct Cl content was obtained for the hexahydrochloride thus prepared was the presence of squalene considered to be established. The squalene content of the various lipids was then estimated by the method described in the preceding paper of this series (Wheatley, 1953 b).

\section{RESULTS}

The general composition of the lipids from these sebum-like materials is shown in Table 1 ; while in Table 2 the results of the chromatographic analysis of the unsaponifiable matter from these lipids is given. The most notable differences between these

Table 1. General properties of some lipids thought to be related to sebum

\begin{tabular}{|c|c|c|c|c|c|c|c|}
\hline & \multicolumn{7}{|c|}{ Source of lipids } \\
\hline & \multirow[b]{2}{*}{ Sebum } & \multicolumn{2}{|c|}{$\begin{array}{l}\text { Ovarian dermoid } \\
\text { cyst }\end{array}$} & \multirow{2}{*}{$\begin{array}{c}\text { Ear wax } \\
\text { (6 specimens) }\end{array}$} & \multicolumn{2}{|c|}{ Vernix caseosa } & \multirow{2}{*}{$\begin{array}{l}\text { Epidermal } \\
\text { cyst }\end{array}$} \\
\hline & & (a) & (b) & & (a) & (b) & \\
\hline M.p. $\left({ }^{\circ}\right)$ & $35-37$ & 34 & 31 & 33-36 & 31 & 32 & - \\
\hline Iodine no. & $53-63$ & 56 & 79 & 34-74 & 46 & 59 & 48 \\
\hline Acid no. & $59-73$ & $0 \cdot 6$ & $0 \cdot 3$ & $47-64$ & $5^{*}$ & 15 & $29^{*}$ \\
\hline Total cholesterol (\%) & $2 \cdot 7-5 \cdot 9$ & $\mathbf{3 \cdot 6}$ & $6 \cdot 8$ & $12 \cdot 1-17 \cdot 1$ & $19 \cdot 7$ & $20 \cdot 6$ & $17 \cdot 4$ \\
\hline Total N (\%) & $0 \cdot 42-0.49$ & Nil & 0.07 & $0 \cdot 9-1 \cdot 92$ & $0 \cdot 32$ & 0.44 & - \\
\hline Lipid P (\%) & Nil & $\mathrm{Nil}$ & Nil & $0.01-0.041$ & $0 \cdot 025$ & $0 \cdot 029$ & 0.093 \\
\hline Free fatty acids (\%) & $22-32$ & $0 \cdot 6$ & 0.5 & $29 \cdot 9-36 \cdot 2$ & $2 \cdot 3$ & $9 \cdot 4$ & $14 \cdot 7$ \\
\hline Combined fatty acids (\%) & $28-41$ & $70 \cdot 2$ & $70 \cdot 8$ & $8 \cdot 9-20 \cdot 8$ & $33 \cdot 3$ & $42 \cdot 1$ & $4 \cdot 3$ \\
\hline Unsaponifiable matter $(\%)$ & $27-36$ & $27 \cdot 3$ & $28 \cdot 2$ & $27 \cdot 0-39 \cdot 7$ & $27 \cdot 0$ & $48 \cdot 6$ & $57 \cdot 7$ \\
\hline Squalene $(\%)$ & $3 \cdot 3-8 \cdot 7$ & $3 \cdot 7$ & $10 \cdot 2$ & $1 \cdot 0-12 \cdot 0$ & & & Nil \\
\hline
\end{tabular}


Table 2. The composition of the unsaponifiable matter of the sebum-like material (\%)

\begin{tabular}{|c|c|c|c|c|c|c|}
\hline & & & Sour & & & \\
\hline & & Ovari & id cyst & & & \\
\hline Fractions & Sebum & (a) & (b) & (a) & (b) & $\begin{array}{l}\text { vernix } \\
\text { caseosa }\end{array}$ \\
\hline Hydrocarbons & $37-46$ & $13 \cdot 2$ & $39 \cdot 0$ & $18 \cdot 3$ & $9 \cdot 3$ & $6 \cdot 4$ \\
\hline Wax alcohols & $17-25$ & $56 \cdot 2$ & 41.2 & $19 \cdot 6$ & $22 \cdot 0$ & $13 \cdot 0$ \\
\hline III. Cholesterol & $14-19$ & $11 \cdot 8$ & $14 \cdot 8$ & $33 \cdot 8$ & 30.0 & 40.5 \\
\hline IV. Sterol-like substances & 4-11 & $7 \cdot 8$ & $3 \cdot 1$ & $6 \cdot 3$ & $10 \cdot 2$ & $12 \cdot 3$ \\
\hline V. Unidentified & $6-13$ & $7 \cdot 8$ & $2 \cdot 1$ & 18.9 & $18 \cdot 1$ & $16 \cdot 5$ \\
\hline
\end{tabular}

lipids and sebum are the following. Free fatty acids are absent from dermoid cyst lipids while they are present in ear wax and vernix caseosa. The cholesterol content of ear wax and vernix caseosa is much higher than sebum. The hydrocarbon fraction is larger in sebum than in any of the other materials examined. There is a higher proportion of waxes in dermoid cyst lipid than in sebum, ear wax or vernix caseosa.

\section{Examination of unsaponifiable matter}

The various fractions obtained in the chromatographic analysis were further investigated. The composite results of these studies are recorded; where differences were observed between different specimens these have been indicated. Owing to the small amount of material available only a cursory examination of the fractions from ear wax and vernix caseosa could be made, but with the dermoid cyst lipids a much more detailed investigation was possible.

\section{Dermoid cyst}

Fraction $I$. This was a colourless viscous liquid which was composed largely of squalene (specimen 1 , $88 \%$; specimen $2,81 \%$ ). Urea adduct formation (Zimmerscheid, Dinerstein, Weitkamp \& Matschner, 1950) showed the presence of only about $1 \%$ $n$-paraffins, and recrystallization from ethanol of the residue after removal of squalene gave only a small amount of solid hydrocarbons.

Fraction $I I$. The crude fraction was a grey-white wax (m.p. $49 \cdot 5^{\circ}$, specimen $1 ; 51 \cdot 4^{\circ}$, specimen 2 ) which on recrystallization from acetone gave a white wax m.p. $65 \cdot 6^{\circ}$ (specimen l); $60 \cdot 0^{\circ}$ (specimen 2 ). When large batches $(20 \mathrm{~g}$.) of unsaponifiable matter were fractionated on a long column $(250 \mathrm{~g}$. alumina) the first specimen showed three principal fractions. (a) A brown gum (4.4\% of total unsaponifiable matter), iodine number 102 , acetyl number 18, which failed to form an insoluble urea adduct. This was probably an oxidation product of squalene. (b) A soft white wax (18.9\% of total unsaponifiable matter) iodine number 40 , which when subjected to urea adduct formation (Tiedt \& Truter, 1952) was shown to be composed of $32 \%$ $n$-alcohols (m.p. $48 \cdot 2^{\circ}$, iodine number 23 ) and liquid branched-chain alcohols (iodine number 47). (c) A hard white wax $(33.3 \%$ of total unsaponifiable matter) iodine number 13, composed of $41 \% n$ alcohols (m.p. 62.8 ${ }^{\circ}$; iodine number 3) and solid branched-chain alcohols (m.p. $55^{\circ}$, iodine number 18). The second specimen gave two fractions: (a) a soft white wax composed of $38 \% n$-alcohols (m.p. 53. $8^{\circ}$, iodine number 30 ) and liquid branchedchain alcohols (iodine number 40) and $(b)$ a hard white wax composed of $39 \% n$-alcohols (m.p. $61 \cdot 8^{\circ}$, iodine number 3 ) and solid branched-chain alcohols (m.p. 42.8 ${ }^{\circ}$, iodine number 21 ).

Fraction III. This was composed of almost pure cholesterol which was characterized as the dibromide (m.p. $117-18^{\circ}$ ) and the acetate (m.p. $114^{\circ}$ ). Estimation by Schönheimer's (1930) method showed that it contained a small amount $(2 \cdot 1 \%$ specimen 1 ; $1.6 \%$ specimen 2 ) of saturated sterol (probably $\beta$-cholestanol). The crude fraction gave a doubtfully positive Rosenheim test with large amounts (20-30 mg.) of material.

Fraction $I V$. The crude fraction was a brown gum which gave positive Rosenheim and $\mathrm{SbCl}_{3}$ reactions, it was not found possible to crystallize either the crude material or the material resulting from benzoylating the crude fraction.

Preliminary investigations of the fraction were conducted on the first specimen. Careful chromatography of the crude fraction on a long column $(30 \mathrm{~cm}$.) of alumina gave a white solid fraction which gave a very strongly positive $\mathrm{SbCl}_{3}$ test, but neither this material nor that resulting from benzoylation could be induced to crystallize. The benzoate gave a blue colour with acetic acid and $\mathrm{H}_{2} \mathrm{SO}_{4}$ (Haslewood 1939). When a further batch of the crude fraction was treated with digitonin in $95 \%$ ethanol an insoluble digitonide was obtained. This digitonide on treatment with pyridine and ether yielded a brown gum, but neither the gum nor the material resulting from benzoylating the gum could be induced to crystallize, and chromatography of the benzoylated material on alumina failed to achieve a purification. It was subsequently shown that when a paper chromatogram of the principal fraction, obtained by this chromatography, was run, two blue spots 
were obtained $\left(R_{F} \mathbf{0} .86\right.$ and 0.75 with benzene-light petroleum), the latter corresponding to 7- $\alpha$ hydroxycholesterol benzoate. It was also observed that the 'digitonin' recovered from the digitonide after treatment with pyridine and ether still gave a positive $\mathrm{SbCl}_{3}$ test and contained a digitonide not decomposed by this treatment. The material not precipitated from the crude fraction by digitonin gave brown colorations with the LiebermannBurchard, Rosenheim and $\mathrm{SbCl}_{3}$ tests and when a paper chromatogram of the material was run (chloroform) no blue spot was observed.

The fractions obtained by chromatography of $20 \mathrm{~g}$. batches of unsaponifiable matter $(250 \mathrm{~g}$. column) were examined in the following manner. With specimen 1, paper chromatograms were run (chloroform) on each portion of eluate; a blue spot was observed with some of these fractions. These fractions were pooled and the pooled material $\mathbf{( 3 . 3} \%$ of the total unsaponifiable matter) which contained $19 \%$ sterol (calculated as cholesterol) was treated with digitonin. The preliminary separation was omitted with the second specimen and the whole of the crude fraction was treated with digitonin. The digitonides from both specimens were treated with pyridine and ether, when a brown gum was obtained $(0 \cdot 3 \%$ total unsaponifiable matter with specimen 1 and $0.06 \%$ with specimen 2$)$. This gum was benzoylated and when paper chromatograms were run on the benzoylated material, a single blue spot was obtained $\left(R_{F} \mathbf{0} \cdot 90\right.$, benzenelight petroleum) which was not identical with 7 - $\alpha$-hydroxycholesterol benzoate $\left(R_{F} 0 \cdot 70\right)$. The fraction was not pure, as the paper chromatogram showed an intense brown streak at the origin. The digitonide was then refluxed with xylene for $6 \mathrm{hr}$. when complete decomposition was effected. A gum was recovered after removal of the xylene in vacuo $\mathbf{( 0 . 2 9} \%$ total unsaponifiable matter in specimen 1 and $0.12 \%$ in specimen 2 ). This gum was benzoylated and paper chromatograms were run on the benzoylated material. The two specimens gave different results. The first specimen gave four principal constituents, three gave blue spots $\left(R_{F}\right.$ $1.0,0.85,0.55$ with benzene-chloroform) and one lilac spot $\left(R_{F}, 0.91\right)$ while the second specimen contained three constituents, one a blue spot $\left(R_{\boldsymbol{F}} \mathbf{0 . 4 9}\right)$ and two lilac spots $\left(R_{F} 0.87\right.$ and 0.56$)$; traces of other constituents were also observed.

The fraction therefore contained several sterols or sterol-like substances which form insoluble digitonides. The digitonide of one of these is decomposed by treatment with pyridine and ether, the sterol was not identical with 7- $\alpha$-hydroxycholesterol but may be oxidized to this substance. The other sterols form digitonides which are decomposed only by boiling xylene. It has not been possible to isolate a crystalline substance from any fraction, possibly owing to the complex nature of the mixture.

Fraction $V$. A dirty white solid which on recrystallization from methanol gave a white solid m.p. $79^{\circ}$ (specimen 1); $78^{\circ}$ (specimen 2).

\section{Ear wax}

Fraction I. A white viscous liquid containing about $85 \%$ squalene. After removal of the squalene the residue was crystallized from ethanol to give a small amount of solid hydrocarbon. Fraction $I I$. A dirty white material which on recrystallization from acetone gave a white wax, m.p. $47^{\circ}$. Fraction III. Almost pure cholesterol, characterized as the acetate (m.p. $113^{\circ}$ ) and the dibromide (m.p. 117-18 ${ }^{\circ}$. Fraction $I V$. A brown gum which gave positive Rosenheim and $\mathrm{SbCl}_{3}$ tests. Paper chromatography of the crude fraction showed a blue spot corresponding to that obtained with the same fraction from sebum. Fraction $V$. Recrystallization of the crude fraction from methanol gave a white solid m.p. $78-81^{\circ}$.

\section{Vernix caseosa}

Fraction $I$. This consisted of practically pure squalene and a trace of solid hydrocarbons. Fraction II. On recrystallization of the crude fraction from acetone a white wax m.p. $58 \cdot 8^{\circ}$ was obtained. Fraction III. Practically pure cholesterol which was characterized as the acetate (m.p. $114^{\circ}$ ). Fraction $I V$. The crude fraction gave positive Rosenheim and $\mathrm{SbCl}_{3}$ colorations but paper chromatography failed to reveal the presence of a blue spot corresponding to sebum. Fraction $V$. This resembled the corresponding fraction obtained from sebum.

\section{Epidermal cyst}

There was insufficient material to subject to full chromatographic analysis. The absence of squalene was established and only a negligible amount of hydrocarbon could be detected.

\section{DISCUSSION}

An examination of the composition of four lipid materials thought to be related to sebum showed striking similarity in most cases, though definite differences were also shown to exist. It is interesting that dermoid cyst lipid, ear wax and vernix caseosa all contain a smaller hydrocarbon fraction than sebum and this is composed largely of squalene. The corresponding fraction from sebum contains only about $50 \%$ squalene, the remainder being largely $n$-paraffins. It has been established that dermoid cyst lipid contains very little of $n$-paraffins, and there is a suggestion that only a small amount may be present in ear wax and vernix caseosa. It is therefore possible that the $n$-paraffins found in 
sebum do not originate from the sebaceous glands and may be contaminants.

The large amounts of material available from the two dermoid cysts have enabled the unsaponifiable matter from this lipid to be investigated in greater detail than has yet been possible with sebum. When large samples of unsaponifiable matter were fractionated on long columns of alumina the wax alcohols tended to separate, the shorter-chained and unsaturated members travelling more rapidly than the longer-chained saturated ones. Urea adduct formation showed that the mixed fraction contained about $38 \% n$-alcohols (10\% of which were unsaturated) and branched-chain alcohols (30\% of which were unsaturated). Various $n$ alcohols have been claimed to be present in dermoid cyst lipid, namely tetradecanol (Dimter, 1941), hexadecanol (Ludwig, 1897), eicosanol (Ameseder, 1907) and docosanol (Dimter, 1941). Mass spectrometry of the wax alcohols from human-hair lipid (Nicolaides \& Rothman, 1953) has shown that the straight-chain alcohols exist as a homologous series ranging from $\mathrm{C}_{18}$ to $\mathrm{C}_{26}$ with odd as well as even members present. It has not been possible to submit the fractions from dermoid cyst lipid to mass spectrometry but it is considered highly possible that a similar homologous series exists in this material; this would easily explain the confused picture of the nature of the wax alcohol obtained by earlier workers. There is also some indication that the fractions from the two specimens of cyst lipid were slightly different.

Careful examination of the cholesterol and the following fraction from dermoid cyst lipid has revealed the presence of several sterols or related substances. The presence of a small amount only of saturated sterol ( $\beta$-cholestanol) has been established, though Behmel (1932) claimed that this substance was present 'in abundance'. An indication has been obtained for the first time with any sebaceous substance that 7-dehydrocholesterol or a similar substance may be present. Several sterols were found to be present in fraction IV, which formed insoluble digitonides. The digitonide of one of these was decomposed on being treated with pyridine and ether. This was not identical with $7-\alpha$-hydroxycholesterol, but in one batch of material that had been subjected to somewhat involved manipulation the unknown sterol was found to be accompanied by the latter substance. It could therefore be related to $7-\alpha$-hydroxycholesterol and yield this substance on oxidation. The digitonides of the other sterols required treatment with boiling xylene to decom. pose them, at least three components were present and these were not identical in the two specimens of lipid examined. It is possible that certain of the substances are oxidation products of sterols present in the original material and it is proposed to in- vestigate the problem in greater detail when larger supplies of material become available.

Summarizing the results of the examination of these sebum-like materials, we may say that ear wax resembles sebum that has been oxidized and contaminated with extraneous cholesterol and other substances. Vernix caseosa gives the picture one would expect of the sebum of an immature animal, for it has been shown by Nicolaides \& Rothman (1952) that in the hair lipids of children the cholesterol content is higher and the squalene content lower than that from adults. Furthermore, the material probably contains sterol-like substances of maternal origin. Both ear wax and vernix caseosa can be regarded as of sebaceous origin; on the other hand, the epidermal cyst lipid is different from sebum and it is unlikely that this substance originates from true or modified sebaceous glands.

The dermoid cyst lipid resembles sebum in many ways but there are several differences that are not easily explained. One such difference is the absence of free fatty acids. It has been shown by Nicolaides \& Rothman (1953) that the free fatty acid content of human hair lipid increases on storage, the liberated acids being formed by hydrolysis of the triglycerides present, and it is possible that the free fatty acids of human sebum may originate in such a manner by bacterial or other hydrolysis. Such hydrolysis would not occur in dermoid cyst lipid; but neither should it occur in vernix caseosa which has been shown to contain some free fatty acids even though less were present than in sebum. The presence of a much larger proportion of true waxes in dermoid cyst lipid is equally difficult to explain. Furthermore, there is strong evidence both from this examination of two specimens of the lipid and from the investigations of other workers that different samples of this lipid material vary appreciably in composition. The most likely interpretation of all these observations is that the lipid in dermal cysts represents a 'sebum' produced by a pathological process.

\section{SUMMARY}

1. Certain substances thought to be related to sebum (ear wax, vernix caseosa, dermoid and epidermal cyst lipids) have been examined and their composition compared with that of sebum.

2. It is concluded that ear wax and vernix caseosa are related to sebum and originate from true or modified sebaceous glands, that epidermal cyst lipid is not related to sebum and that dermoid cyst lipid represents a 'sebum' produced by a pathological process.

3. The unsaponifiable matter from the contents of two dermoid cysts has been examined in detail. The presence of straight- and branched-chrin 
alcohols has been established. Some saturated sterol (probably $\beta$-cholestanol) is present and a number of other sterol or sterol-like substances which form insoluble digitonides have been found.

The author wishes to thank Dr R. M. B. MacKenna and Professor A. Wormall for their interest and help. The two specimens of ovarian dermoid cyst lipid were kindly supplied by Dr Magnus Haines of the Chelsea Hospital for Women, the ear wax and vernix caseosa specimens by the Ear, Nose and Throat and Maternity departments of St Bartholomew's Hospital, and the epidermal cyst by Dr I. S. Hodgson-Jones.

\section{REFERENCES}

Ameseder, F. (1907). Hoppe-Seyl. Z. 52, 121.

Behmel, G. (1932). Hoppe-Seyl. Z. 208, 62.

Bush, I. E. (1952). Biochem. J. 50, 370.

Dimter, A. (1941). Hoppe-Seyl. Z. 270, 247.

Fiske, C. H. \& Subbarow, Y. (1925). J. biol. Chem. 66, 375.
Haslewood, G. A. D. (1939). Biochem. J. 33, 709.

Hodgson-Jones, I. S. \& Wheatley, V. R. (1952). Biochem. J. $52,460$.

Kelsey, F. E. (1939). J. biol. Chem. 127, 15.

Ludwig, E. (1897). Hoppe-Seyl. Z. 23, 38.

MacKenna, R. M. B., Wheatley, V. R. \& Wormall, A. (1950). J. invest. Derm. 15, 33.

MacKenna, R. M. B., Wheatley, V. R. \& Wormall, A. (1952). Biochem. J. 52, 161.

Nicolaides, N. \& Rothman, S. (1952). J. invest. Derm. 19, 389.

Nicolaides, N. \& Rothman, S. (1953). J. invest. Derm. $21,9$.

Schönheimer, R. (1930). Hoppe-Seyl. Z. $192,77$.

Sotnitchewsky (1880). Hoppe-Seyl. Z. 4, 345.

Tiedt, J. \& Truter, E. V. (1952). J. chem. Soc. p. 4628.

Wheatley, V. R. (1951). Nature, Lond., 168, 1128.

Wheatley, V. R. (1953a). Biochem. J. 53, xxi.

Wheatley, V. R. (1953b). Biochem. J. 55, 637.

Zimmerscheid, W. J., Dinerstein, R. A., Weitkamp, A. W. \& Matschner, R. F. (1950). Industr. Engng Chem. (News), $42,1300$.

\title{
The Vitamin D Content of Tissues of Rats given Ergocalciferol
}

\author{
By E. M. CRUICKSHANK AND E. KODICEK \\ Dunn Nutritional Laboratory, University of Cambridge, and Medical Research Council \\ AND P. ARMITAGE \\ Statistical Research Unit of the Medical Research Council, London School of Hygiene and Tropical Medicine, \\ University of London
}

(Received 23 April 1954)

In previously reported balance experiments, in which rachitic rats were given a single massive dose of $1 \mathrm{mg}$. of ergocalciferol, it was found that only about $6 \%$ was recovered in the body (Cruickshank, Kodicek \& Armitage, 1953). About half of it was present in the liver, which therefore appeared to be the principal store of the absorbed vitamin. It was impracticable in that investigation to examine the distribution in all the individual organs and tissues but the possibility existed that some organs, though small in size and therefore contributing little to the total content, might nevertheless have a relatively high concentration. Subsequent work, already briefly reported (Cruickshank \& Kodicek, 1952), showed that this was so and details of the experiments are now presented.

\section{EXPERIMENTAL}

The design of the experiments is shown in Table 1. The experimental procedure was that already described (Cruickshank et al. 1953). Groups of rachitic rats were given by mouth $1 \mathrm{mg}$. crystalline ergocalciferol/rat and the vitamin $D$ content of various organs in the fresh state, 24 and $48 \mathrm{hr}$. after dosing, was determined biologically on rats by the radiographic method of Bourdillon, Bruce, Fischmann \& Webster (1931).

The determination of vitamin $D$ was carried out in three series of assays, in which about 200 rats were used. The ranges of doses, in mg. of fresh material, were as follows: muscle, 100-1000; skin, 200-1000; kidneys, lungs and spleen, 15-60; brain, 125-500; adrenals, 32. Since in the previous work the whole carcass from undosed rachitic rats contained little or no vitamin D (Cruickshank et al. 1953), it was considered unnecessary to assay the individual organs of undosed animals with the exception of the adrenals, which when assayed were found to contain no vitamin $\mathbf{D}$.

\section{Table 1. Design of experiments}

Each rat received $1 \mathrm{mg}$. ergocalciferol

\begin{tabular}{|c|c|c|c|c|}
\hline Expt. & $\begin{array}{l}\text { No. of } \\
\text { rats }\end{array}$ & $\operatorname{Sex}$ & $\begin{array}{l}\text { Day of } \\
\text { killing }\end{array}$ & Tissues investigated \\
\hline 1 & 5 & $\begin{array}{l}3 \mathrm{M} . \\
2 \mathrm{~F} .\end{array}$ & lst & Muscle, skin, kidneys \\
\hline 2 & 5 & $\begin{array}{l}3 \mathrm{M} . \\
2 \mathrm{~F} .\end{array}$ & 2nd & $\begin{array}{l}\text { Muscle, lungs, spleen, } \\
\text { kidneys, adrenals }\end{array}$ \\
\hline 3 & 6 & $\begin{array}{l}3 \text { M. } \\
3 \text { F. }\end{array}$ & 2nd & Muscle, skin, brain \\
\hline
\end{tabular}

